\title{
Phenolic Compounds Content in Merlot Wines Obtained through Different Thermomaceration Techniques
}

\author{
Marius NICULAUA ${ }^{1}$, Ștefan TUDOSE-SANDU-VILLE ${ }^{2}$, \\ Valeriu V. COTEA ${ }^{2}$, Camelia E. LUCHIAN², \\ Ovidiu-Florin TUDOSE-SANDU-VILLE ${ }^{3 *}$ \\ ${ }^{I}$ Romanian Academy of Sciences, Center of Oenological Researches, Iași Branch, 9 M. Sadoveanu Alley, 700490 Iaşi, \\ Romania;niculaua@gmail.com \\ ${ }^{2}$ University of Agricultural Sciences and Veterinary Medicine Iași, 3 M. Sadoveanu Alley, 700490 Iași, Romania; stefan_ville@yahoo.com; \\ vvcotea@yahoo.com;kamelia_luchian@yahoo.com \\ ${ }^{3 ‘}$ 'Gheorghe Asachi' Technical University of Iaşi, 67 Professor Dimitrie Mangeron Blvd, 700050 Iaşi, \\ Romania; florintsv@yahoo.com (*correspondingauthor)
}

\begin{abstract}
This paper's objectives were to determine the anthocyanic extraction level and their distribution by correlating the total phenolic content with different thermic maceration techniques applied to 'Merlot' grapes. In this study, three maceration processes were employed: thermoflash maceration (thermobaric), thermomaceration, and also classical macerationfermentation, in order to compare the extraction degree of anthocyans from red grape skins into wine. In order to determine the sample's anthocyan profile, a standard HPLC method of analysis (OIV-MA-AS315-11) was used. The wines obtained through thermoflash maceration contain significantly higher quantities of phenolic compounds ( $3572 \mathrm{mg} \mathrm{GAE} \mathrm{L}^{-1}$ ) and total anthocyans $\left(340 \mathrm{mg} \mathrm{L}^{-1}\right)$, in contrast with the classical maceration-fermentation winemaking technology. Also, the participation percentage in the anthocyanic profile of malvidin-3-monoglicoside, an intense blue-purple coloured pigment is $60.1 \%$ and is with $10 \%$ superior to classical method of maceration. The obtained wines were characterised through high degree of stability for the anthocyans due to high values for the ratio between the acetylated and coumarylated anthocyans (9.36).
\end{abstract}

Keywords: anthocyanic profile, polyphenol, thermoflash maceration

Abbreviations: mg GAE - mg Gallic Acid Equivalent; TPI - Total Polyphenolic Index; HPLC - High Performance Liquid Chromatograph; FTIR - Fourier-Transform Infrared Spectroscopy; LC - Liquid Chromatography; UV-VIS - Ultraviolet Visible Spectroscopy; Cy-3-gl - cyanidol-3-glucoside; De-3-gl - delphinidol-3-glucoside; Mv-3-acgl - malvidol-3acetylglucoside; Mv-3-cugl - malvidol-3-coumarylglucoside; Mv-3-gl - malvidol-3-glucoside; Po-3-acgl - peonidol-3acetylglucoside; Po-3-cugl - peonidol-3-coumarylglucoside; Po-3-gl - peonidol-3-glucoside; Pt-3-gl - petunidol-3-glucoside; Eest.ant. - esterified anthocyans percentage sum; $\sum \mathrm{ac} / \sum \mathrm{cu}$ - percentage ratio of acetylated anthocyanidin-3-glucosides to coumarylated anthocyanidin-3- glucosides; $\sum$ estMv/Mv- esterification ratio of malvidol-3-glucoside; $\sum$ estPo/Po esterification ratio of peonidol-3-glucoside; $\sum$ est/ $\sum$ nest- peonidol-3-glucoside and malvidol-3-glucoside overall ratio of esterification; $\boldsymbol{\sigma}-$ standard deviation; $\overline{\mathrm{x}}-$ average values

\section{Introduction}

Wines represent one of the traditional products in Romania for centuries that are underestimated and little known on international level. More than that, the Romanian wine industry is slowly but steadily aligning itself to modern technologies; this research's aim being that of contributing on speeding up this process. Worldwide, the wine industry must answer newer challenges generated by the refinement of the consumers taste; also, recent discoveries on the beneficial impact of phenolic compounds in red wines on human metabolism must be thoroughly researched (Ignat et al., 2016).

In oenology, polyphenolic compounds hold an important place because they influence the colour and the taste of wines, like astringency, asperity and fragrance. Some compounds act similar as the $\mathrm{P}$ vitamin does in the human body and most of them have antibacterial effect. Moreover, 
the polyphenolic compounds in black grapes and red wines are proven to have a highly beneficial effect on preventing certain forms of cancer and most of the heart diseases.

Black grapes, especially the Vitis vinifera varieties, can contain significant quantities of polyphenolic compounds. These substances are found mostly in the solid parts of the grape, thus making an extraction process indispensable if one wants to obtain wines rich in these compounds. This process is known as maceration and it consists of using physical and chemical methods that aim at transferring the polyphenolic compounds from grape seeds and skins to must.

The maceration process can be enhanced by controlling certain physical parameters like temperature or pressure, and some chemical factors like alcohol content (if the fermentation process develops simultaneously with the maceration), sulphur dioxide content or carbon dioxide content. These findings generated a wide array of technological variants used worldwide in obtaining red wines such as: classical maceration and rotating-tank maceration, carbonic maceration, thermomaceration and microwave maceration (Tudose-Sandu-Ville et al., 2012) and also highly experimental methods like cryomaceration (Peinado et al., 2004) and 'flash détente' (or 'thermoflash') maceration (Vinsonneau et al., 2006; Samoticha et al., 2017).

The aim of the research was to pilot an innovative technological wine-making process in extracting the highest quantities possible of phenolic compounds (phenolic acids, anthocyans and tannins) from black grape's skins and seeds. At this point, many advanced technologies, which produce fairly good results in obtaining red wines with high polyphenolic contents are known and are being used worldwide. Recent studies show that the most proficient maceration technique discovered yet is the baric shock method, which consists in applying a high pressure differential in the grapes (from 1 bar to 0,05 bar) in a very short time (under 1 second); this has a violent effect on the cells, which literarily explode, releasing their contents.

This newly proposed baric shock maceration technology is considered to be the most efficient in extracting polyphenolic compounds from grapes, because it employs a pressure shock at high temperatures and it produces high quality red wines with insignificant quality loss. Thus, the aim of the present research was to test the effectiveness of the innovative thermobaric technology on 'Merlot' grapes harvested form Iasi vineyard, regarding the fact that this method was never employed yet in Romania.

\section{Materials and Methods}

\section{Wine samplesproduction}

Research concerning the influence of different maceration-fermentation technological processes on the extraction degree for phenolic compounds from red grapes has been conducted in the Oenology Laboratory of the University of Agricultural Studies and Veterinary Medicine Iași, Romania. Therefore, Merlot grapes have been harvested from Iași-Şorogari vineyard and were processed by using three maceration fermentation techniques: classical maceration (V0), thermobaric-maceration (V1), and thermomaceration (V2).
The characteristics of each experimental technique used were:

Classical maceration (V0): selected yeasts (Saccharomyces cerevisiae - Fermactive Rouge Expression") were added to the must, which was in contact with the skins for 5 days at $18{ }^{\circ} \mathrm{C}$; when the alcoholic concentration reached $9 \%(\mathrm{v} / \mathrm{v})$, the must was separated from the skins and the fermentation process continued until all sugars were depleted (Ribéreau-Gayon et al., 2006).

The baric shock, or thermobaric method (V1) could be considered a thermomaceration technique, which utilizes a pressure shock, using vacuum; in this case, the pressurised injection method was used, in order to achieve the desired low pressure gradient. The crushed and destemmed grapes were quickly heated up to $80-82{ }^{\circ} \mathrm{C}$ by recirculating the drained must through a heating unit. The heated marc is then introduced in the baric chamber. This is a stainless steel (at least $4 \mathrm{~mm}$ thick) vat comprised of two levels, separated by a pressure valve. The receiving bin is connected to a pump and the entire device works continuously, assisted by two peristaltic pumps. In the upper part, the rapid cellular content release will take place, and also a drop of temperature by $5{ }^{\circ} \mathrm{C}$ will be registered. The process lasts less than 3 minutes. A diagram of the entire process is shown in Fig. 1. After the applied technique, the rest of the winemaking process was conducted as in the previous variant.

In thermomaceration (V2), the grape marc was subjected to a thermal treatment at $82^{\circ} \mathrm{C}$, for half an hour. In order to reach the desired temperature, 6 meter heat exchangers were used (tank capacity $100 \mathrm{~kg}$, maximum productivity $500 \mathrm{~kg} \mathrm{~h}^{-1}$, and $10 \mathrm{~kW}$ power). The minimal threshold for marc thermal treatment is $80{ }^{\circ} \mathrm{C}$. After the thermal treatment, the fermentation process took place as described in the case of the classical method (V0) (Cotea and Sauciuc, 1988; Tudose-Sandu-Ville and Tărăboanță, 2002).

Many technological operations used were common to all variants: crushing and total destemming, $\mathrm{SO}_{2}$ treatment of the marc (doses of $0.05 \mathrm{~g} \mathrm{~L}^{-1}$ ) in order to insure antioxidant and antiseptic protection, proteolytic enzymes addition in order to increase fluid extraction, adding the same yeast to the must; the marc was pressed using a low-capacity pneumatic press, fermentation, followed by a clarifying treatment, racking, filtration with a sterile filter and bottling (Cotea and Cotea, 2006).

\section{Physicochemical parameters}

For the evaluation of the main compositional characteristics of the proposed experimental variants, an OenoFoss FTIR Spectrophotometer was used; thus, the results are presented in Table 1 .

An UV-VIS Analytik Jena Specord 200 spectrophotometer was utilised for evaluating the total phenolic content and anthocyans. Thus, the total polyphenolic index is utilised for the evaluation of the total polyphenol content, relative to gallic acid equivalent (mg $\left.\mathrm{GAE} \mathrm{L}^{-1}\right)$.

The vials used for sampling were washed with $2 \mathrm{~mL}$ of water tree times and then all samples were filtered through $0.45 \mu \mathrm{m}$ nylon with a $25 \mathrm{~mm}$ syringe filters, prior to the LC analysis, in order to remove any colloids. The LC analysis 
550

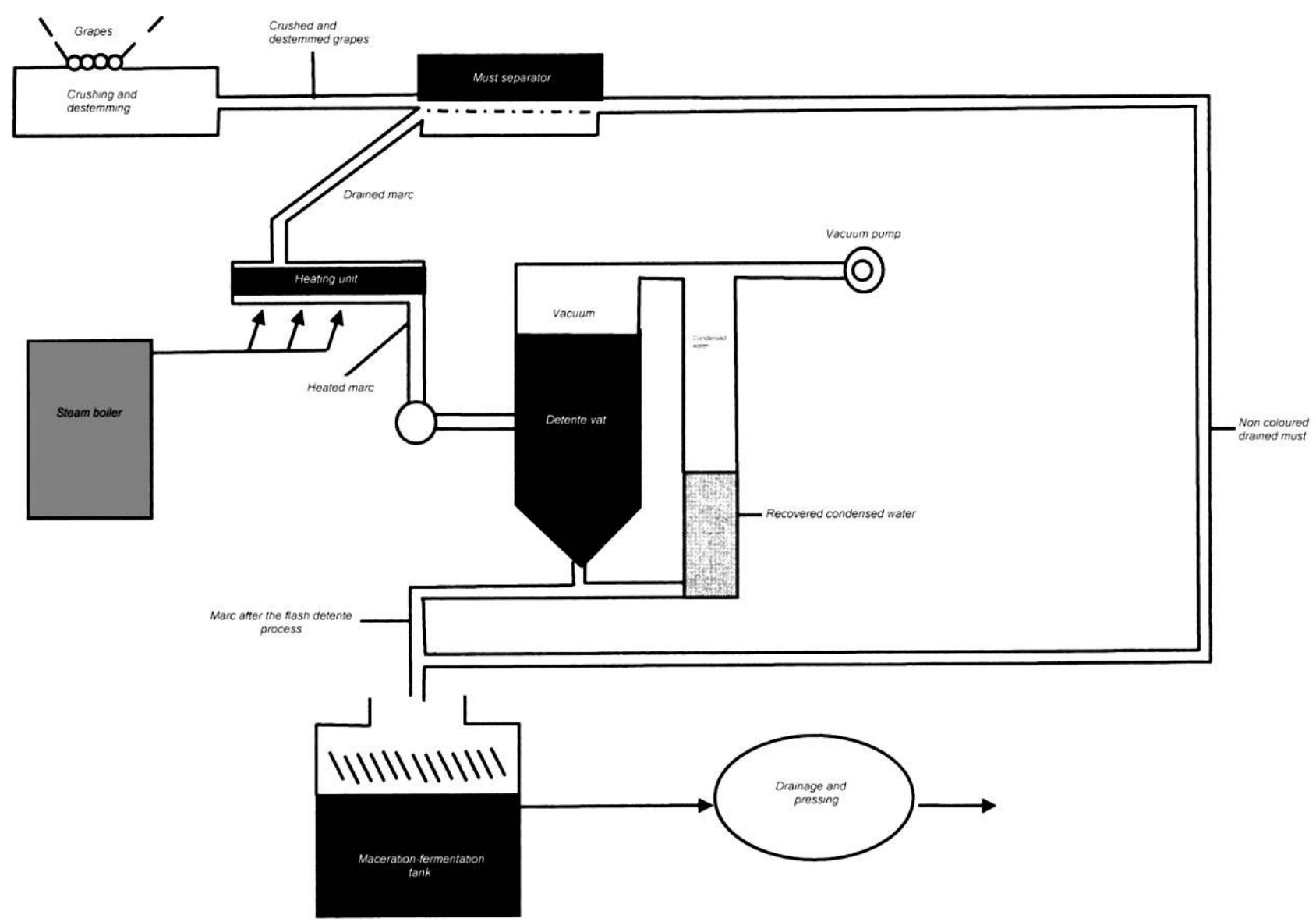

Fig. 1. Thermoflash maceration technique (Pomohaci et al., 2000)

was performed using a fused core silica column according to the OIV-MA-AS315-11 method. A Kinetex $2.4 \mu \mathrm{m}$ column with a octadecylsilane as stationary phase, $96 \AA$ pore medium diameter at $90 \%$ distribution, with geometrical parameters of $150 \times 4.6 \mathrm{~mm}$ (length $\times$ diameter) produced by Phenomenex Inc were used. For the analysis of anthocyans, samples were processed using an Agilent 1100 HPLC consisting of: binary pump with four-channel degasser, an autoinjector (injection volume: $7 \mu \mathrm{L}$ ), a column oven, an UV-VIS detector at $525 \mathrm{~nm}$ and a computer.

The LC system flow rate was $1 \mathrm{~mL} / \mathrm{min}$ and generated 187 bar of backpressure at $45^{\circ} \mathrm{C}$. The new gradient begun at $6 \%$ of $50 \%$ acetonitrile (10\% formic acid pH 1.7 - mobile phase B), increased to $25 \%$ in 5 minutes, continued to increase to $45 \%$ in the next 2 minutes, to $60 \%$ in the next 3 minutes and at the end decreases back to $6 \%$ within 5 minutes. Column equilibration was reached in 4 minute at $6 \%$. The detection wavelength of $525 \mathrm{~nm}$ was utilized because it presented better symmetry for all the picks. All samples were injected in triplicate, as well as diluted to half with mobile phase A (3\% acetonitrile in $10 \%$ formic acid at $\mathrm{pH}$ 1.7) prior to filtration (OIV, 2017).

\section{Results and Discussion}

The alcoholic content of the samples varied in a relative small amount because the raw matter was processed identically for all the samples, thus the technological influence in this regard was minimal (Table 1). The slight discrepancy in the alcoholic content between V1 and V0 can be explained by a possible malo-alcoholic fermentation;

Table 1. Main compositional characteristics of proposed samples

\begin{tabular}{|c|c|c|c|c|c|c|c|c|c|c|c|c|c|c|c|c|}
\hline \multirow[t]{2}{*}{ Sample } & \multicolumn{2}{|c|}{$\begin{array}{l}\text { Ethanol } \\
\text { (\% vol.) }\end{array}$} & \multicolumn{2}{|c|}{$\begin{array}{l}\text { Total acid } \\
\text { (g tartaric } \\
\left.\text { acid } \mathrm{L}^{-1}\right)\end{array}$} & \multicolumn{2}{|c|}{$\begin{array}{l}\text { Malic acid } \\
\qquad\left(\mathrm{gL}^{-1}\right)\end{array}$} & \multicolumn{2}{|c|}{$\begin{array}{l}\text { Lactic acid } \\
\qquad\left(\mathrm{g} \mathrm{L}^{-1}\right)\end{array}$} & \multicolumn{2}{|c|}{$\begin{array}{l}\text { Volatile acidity } \\
\left(\text { g acetic acid } L^{-1}\right)\end{array}$} & \multicolumn{2}{|c|}{$\mathrm{pH}$} & \multicolumn{2}{|c|}{$\begin{array}{l}\text { Glucose/ } \\
\text { fructose }\end{array}$} & \multicolumn{2}{|c|}{$\begin{array}{c}\text { Reducing } \\
\text { substances }\left(\mathrm{g} \mathrm{L}^{-1}\right)\end{array}$} \\
\hline & $\bar{x}$ & 6 & $\overline{\mathrm{x}}$ & 6 & $\bar{x}$ & $\sigma$ & $\bar{x}$ & $\sigma$ & $\overline{\mathrm{x}}$ & 6 & $\bar{x}$ & $\sigma$ & $\overline{\mathrm{x}}$ & $\sigma$ & $\overline{\mathrm{x}}$ & $\sigma$ \\
\hline V0 & 13.1 & 0.1 & 5.6 & 0.1 & 1.13 & 0.06 & 0.13 & 0.06 & 0.52 & 0.02 & 3.45 & 0.01 & 0.28 & 0.03 & 1.32 & 0.1 \\
\hline V1 & 13.9 & 0.1 & 5.3 & 0.1 & 1.06 & 0.03 & 0.07 & 0.06 & 0.15 & 0.01 & 3.55 & 0.01 & 0.24 & 0.01 & 0.91 & 0.1 \\
\hline V2 & 13.3 & 0.1 & 5 & 0.1 & 1.33 & 0.06 & 0.02 & 0.01 & 0.4 & 0.01 & 3.44 & 0.01 & 0.21 & 0.01 & 1.03 & 0.1 \\
\hline
\end{tabular}


this can be further explained by the slight difference between the malic and lactic acids content.

The total acidity of the proposed samples could label the obtained wines as mild acidic ones; this statement can be further enforced by the average $\mathrm{pH}$ values determined, keeping in mind that the normal $\mathrm{pH}$ for wines obtained in the N-E part of Romania is found ranging from 2.8-3.9 (Cotea et al., 2009). The volatile acidity values $(0.15-0.52 \mathrm{~g}$ acetic acid $\mathrm{L}^{-1}$ ) showed that the obtained wines do not have any unwanted bacterial fermentation since the smallest increase in volatile acidity represents a bacterial contamination, which should absolutely be avoided (Ribéreau-Gayon et al., 2006).

The ratio between the two main sugars (glucose and fructose) was below par, this being an indication that the fermentation process was complete (Table 1) and the wine has begun a maturation process (Cotea et al., 2009). Nowadays, wine making technology must take into account consumer preferences that is determined by the level of sweetness versus dryness and the body style (varying from light to full-bodied). Red wines are generally more complex and, although both males and female consumers report a higher preference for sweet wine when younger, and thereafter gravitate towards drier wine styles, but the majority of consumers (generally males) of all ages prefer their wine dry and full-bodied (Bruwer et al., 2011). This indicator was taken into consideration and all samples are fermented to dryness (Table 1) so the phenolic compounds can't be influenced be these parameters (Malien-Aubert et al., 2001).

The anthocyans fingerprint, and also polyphenolic and anthocyanin content can be observed in tables 2 and 3 , one can observe that in the case of the V1 sample, the one obtained by thermobaric maceration, the malvidol-3glucoside content is more than $10 \%$ higher than the recorded values registered in the wines produced using other proposed methods (V0 and V2). By comparison with some initial studies the initial studies (Boulet and Escudier, 1998) it is apparent that the majority of phenolic compound are not anthocyans. Out of all non-esterified anthocyanins, the smallest percentage registered was in the case of cyanidol-3glucoside, a crimson coloured pigment, which is the first one to disappear due to its low content and high stability during maturation (Wang et al., 1997). In the case of the thermobaric maceration technique, seconded by the thermomaceration, this particular anthocyan (cyanidol-3glucoside) registered a higher participation percentage than in the wines obtained through the classical method. By comparison the efficiency of the cooling part for the thermobaric process is superior do to the possible thermodegradation effect (Mori et al., 2006).

The amount of phenolic compounds in the wine samples is influenced directly by the maceration technique used. The total polyphenolic content registered is significantly higher in the case of thermobaric maceration $\left(3,572 \mathrm{mg} \mathrm{GAE}^{-1}\right)$ in comparison to than the other proposed methods. This statement could be further underlined by the similarly high values registered in the case of total anthocyanin content (340 $\mathrm{mg} \mathrm{L}^{-1}$ ) for the same sample. In retrospect, taking into account the overall correlated values in Table 2 one could determine the discrepancy in the total polyphenolic content. Some studies have reported a 30-60\% increase for the total polyphenolic content and total anthocyanin content in comparison to normal maceration technologies (Boulet and Escudier, 1998). These relative high values have been reported for a Grenache wines (Doco et al, 2007) and Mourvedre wines (Morel-Salmi et al, 2006). The total amount of esterified anthocyans in the sample obtained by thermobaric maceration had lower values in comparison to the other proposed techniques and was congruent with the data registered for the corresponding amounts of sample's volatile acidity. On the other hand, there was a larger ratio of acetylated anthocyans in comparison to the coumarylated ones (9.36) in the case of thermobaric maceration.

The ratios between the esters of peonidol-3-glucoside and malvidol-3-glucoside were significantly lower in the case of wines obtained through thermobaric maceration $(0.68$ and 0.34 , respectively), in comparison to the other experimental samples; in time, this can lead to the slight chance of a possible decrease in overall colour intensity of the wine due to polycondensation and/or precipitation (Wang et al., 2003). This was further emphasised by the fact that the ratio between the esterified and the free forms of anthocyans (Mv-3-gl and Po$3-\mathrm{gl}$ ) found in wines obtained through thermobaric maceration was slightly lower than the values registered using the other conventional methods proposed. The possibility to remove aldehydes and alcohols with 6 carbon atoms, which can appear in the pre-fermentative stage and contribute to herbaceous aroma compounds formed during destemming (Mozzon et al., 2006) and can increase the esterification of anthocyans process during fermentation (Razungles, 2010).

Table 2. Free and esterified anthocyans participation percentages

\begin{tabular}{cccccccccc}
\hline Sample & De-3-gl & Cy-3-gl & Pt-3-gl & Po-3-gl & Mv-3-gl & Po-3-acgl & Mv-3-acgl & Po-3-cugl & Mv-3-cugl \\
\hline V0 & 6.82 & 0.52 & 7.59 & 3.85 & 50.06 & 2.68 & 22.19 & 0.7 & 5.59 \\
V1 & 5.87 & 0.85 & 7.15 & 3.37 & 60.1 & 2.27 & 18.2 & 0.02 & 2.17 \\
V2 & 6.06 & 0.71 & 7.23 & 5.48 & 50.88 & 2.92 & 19.57 & 1.15 & 6 \\
\hline
\end{tabular}

Table 3. Total polyphenolic, anthocyanin content and ester distribution in the proposed samples

\begin{tabular}{|c|c|c|c|c|c|c|c|}
\hline Sample & $\begin{array}{l}\text { Total phenolics } \\
\left(\mathrm{mg} \mathrm{GAE} \mathrm{L}^{-1}\right)\end{array}$ & $\begin{array}{c}\text { Total anthocyans } \\
\left(\mathrm{mg} \mathrm{L}^{-1}\right)\end{array}$ & Eant (\%) & $\sum \mathrm{Ac} / \Sigma \mathrm{Cu}$ & $\begin{array}{c}\sum \text { estMv/ } \\
\mathrm{Mv}\end{array}$ & $\begin{array}{c}\text { EestPo/ } \\
\text { Po }\end{array}$ & $\begin{array}{l}\text { Eest/ } \\
\sum \text { nest }\end{array}$ \\
\hline V0 & 2,185 & 248 & 31.16 & 3.95 & 0.55 & 0.88 & 0.58 \\
\hline V1 & 3,572 & 340 & 22.66 & 9.36 & 0.34 & 0.68 & 0.36 \\
\hline $\mathrm{V} 2$ & 2,973 & 312 & 29.64 & 3.15 & 0.5 & 0.74 & 0.53 \\
\hline
\end{tabular}




\section{Conclusions}

The thermobaric method, as a rather innovative maceration technique shadowed the classical maceration process because the obtained wines are highlighted by the high values registered for the total phenolic content and total anthocyans content. The wine obtained by thermobaric maceration had a relatively low amount of volatile acidity, thus being less perishable than the ones obtained through classical maceration methods, although it's possible to have a shorter lifespan, in regard to the possibility of anthocyan polycondensation, followed by precipitation. Furthermore, the participation percentage of malvidol-3-glucoside, the defining anthocyan of red wines, was significantly higher in the samples obtained by using thermobaric maceration, than in the ones produced through more conventional means.

\section{References}

Boulet JC, Escudier JL (1998). Flash-détente. OEnologie, Lavoisier Tec et Doc, Paris, Francepp 797-805.

Bruwer J, Saliba A, Miller B (2011). Consumer behaviour and sensory preference differences: implications for wine product marketing. Journal ofConsumer Marketing28(1):5-18.

Cotea VD, Sauciuc J (1988). Tratat de Oenologie, Vol II: Limpezirea, stabilizarea și îmbutelierea vinului [Oenological Treaty, $2^{\text {nd }} \mathrm{Vol}$ Clarification, stabilization and wine bottling]. Editura Ceres, Bucureşti.

Cotea VD, Zănoagă C, Cotea VV (2009). Tratat de oenochimie, Vol I [Oenochemistry Treatise].Editura Academiei Române, Bucureşti.

Cotea VV, Cotea VD (2006). Tehnologii de producere a vinurilor [Wine making technologies]. Editura Academiei Române, București.

Doco T, Williams P, Cheynier V (2007). Effect of flash release and pectinolytic enzyme treatments on wine polysaccharide composition. J Journal of Agricultural and Food Chemistry 55(16):6643-6649.

Ignat G, Bălan G, Sandu I, Costuleanu CL, Tudose-Sandu-Ville S (2016). study of phenolic compounds in merlot red wines obtained by different technologies. Revistade Chimie 8:1560-1565.

Malien-Aubert C, Dangles O, Amiot MJ (2001). Color stability of commercial anthocyanin-based extracts in relation to the phenolic composition. Protective effects by intra- and intermolecular copigmentation. Journal of Agricultural and Food Chemistry 49(1):170-176.

Morel-Salmi C, Souquet JM, BES M, Cheynier V (2006). Effect of flash release treatment on phenolic extraction and wine composition. Journal of Agricultural and Food Chemistry 54:4270-4276.

Mori K, Goto-Yamamoto N, Kitayama M, Hashizume K (2007). Loss of anthocyanins in red-wine grape under high temperature. Journal of Experimental Botany 58(8):1935-1945.
Mozzon M, Savini S, Boselli E, Thorngate JH (2016). The herbaceous character of wines. Italian Journal of Food Science 28:190-207.

OIV (2017). Compendium of international methods of wine and must analysis - International Organisation of Vine and Wine (OIV). Rue D’Aguesseau, 75008 Paris.

Peinado RA, Moreno J, Bueno JE, Moreno JA, Mauricio JC (2004). Comparative study of aromatic compounds in two young white wines subjected to pre-fermentative cryo-maceration. Food Chemistry 84:585-590.

Pomohaci N, Sârghi C, Stoian V, Cotea VV, Gheorghiță M, Nămoloşanu I (2000). Oenologie, Vol I - Prelucrarea strugurilor și producerea vinurilor [Oenology, Vol I - Grape processing and wine production]. Editura Ceres, Bucureşti pp 77-310.

Razungles A (2010). Managing wine quality. Extraction technologies and winequality. Ed Andy Reynolds, Woodhead Publishing Limited.

Ribéreau-Gayon P, Dubourdieu D, Donèche B, Lonvaud A (2006). Handbook of enology, Vol I - The microbiology of wine and vinifications, $2^{\text {nd }}$ Ed.John Wiley \& Sons, West Sussex, England.

Ribéreau-Gayon P, Glories Y, Maujean A, Dubourdieu D (2006). Handbook of enology, Vol II - The chemistry of wine. Stabilization and treatments, ${ }^{\text {nd }}$ Ed. John Wiley \& Sons, West Sussex, England.

Samoticha J, Wojdyło A, Chmielewska J, Oszmiański J (2016). The effects of flash release conditions on the phenolic compounds and antioxidant activity of Pinot noir red wine. European Food Research and Technology 243(6):999-1007.

Tudose-Sandu-Ville OF, Taraboanta FGh (2002). Experimental research on theromechanical contact fatigue. The Annals of Dunarea de Jos University, Galati, fasc VIII - Tribology 104-107.

Tudose-Sandu-Ville Șt, Cotea VV, Niculaua M, Colibaba C (2012). Grape phenolic evolution study of Cabernet Sauvignon during the maturation period in Iaşi vineyard. Buletinul Institutului Politehnic din Iași, Universitatea Tehnică ‘Gheorghe Asachi’ Iași, Tomul LVII (LXI), fasc 1:151-159.

Vinsonneau E, Escaffre P, Crachereau JC, Praud S (2006). Evaluation du procédé de vinification par flash déténtedans le bordelaise. ITV France Bordeaux-Blanquefortp 23.

Wang H, Cao G, Prior RL (1997). Oxygen radical absorbing capacity of anthocyanins. Journal of Agricultural and Food Chemistry 45:304309.

Wang H, Race JE, Shrikhande JA (2003). Anthocyanin transformation in cabernet sauvignon wine during aging. Journal of Agricultural and Food Chemistry 51:7989-7994. 